\title{
Ensuring Sustainable Development Goal in Rural Africa through Adult Literacy Programme: A Case Study of Technology Usage in Developing Nations
}

\author{
Morakinyo Akintolu ${ }^{1}$, Chinaza Uleanya ${ }^{2, *}$ \\ ${ }^{1}$ UNESCO Chair on ODL, University of South Africa (UNISA), South Africa \\ ${ }^{2}$ Department of Education Leadership and Management, Faculty of Education, University of Johannesburg, South Africa
}

Received September 29, 2020; Revised November 25, 2020; Accepted December 6, 2020

\section{Cite This Paper in the following Citation Styles}

(a): [1] Morakinyo Akintolu, Chinaza Uleanya, "Ensuring Sustainable Development Goal in Rural Africa through Adult Literacy Programme: A Case Study of Technology Usage in Developing Nations," Universal Journal of Educational Research, Vol. 9, No. 4, pp. 713 - 719, 2021. DOI: 10.13189/ujer.2021.090401.

(b): Morakinyo Akintolu, Chinaza Uleanya (2021). Ensuring Sustainable Development Goal in Rural Africa through Adult Literacy Programme: A Case Study of Technology Usage in Developing Nations. Universal Journal of Educational Research, 9(4), 713 - 719. DOI: 10.13189/ujer.2021.090401.

Copyright $\mathrm{O} 2021$ by authors, all rights reserved. Authors agree that this article remains permanently open access under the terms of the Creative Commons Attribution License 4.0 International License

\begin{abstract}
In the year 2015 the United Nations adopted the 17 Sustainable Development Goals (SDGs) in the bid to build the capacity of every citizen and develop the society. Quality Education is one of the goals of the SDGs and, as the world moves from knowledge to digital economy, there is need for all stakeholders' involvement in the education sector to achieve quality education. In this light, the exploratory study aims at how Information and Communication Technology (ICT) has supported adult literacy programme in achieving Sustainable Development Goal 4 (Quality Education) in developing nations which are predominantly African countries. In the case of this study, the focus is on rural parts of African nations. The study as well emphasized the integration of ICT into Adult Literacy Programme (ALP) by showing interventions of technology usage in Adult Literacy Programmes (ALP) and concluded by highlighting the lessons learnt from these interventions. Following the findings, the study recommends amongst others that all stakeholders in education should look beyond the traditional education lens and embrace the usage of digital inclusivity for improved literacy education and lifelong learning. Also, government support for Adult Literacy Programmes (ALP) by funding various initiatives that support same should be increased. Collaborative efforts across several governments such as the Department of Information Communication and Technology (DICT), and Department
\end{abstract}

of Adult Education (DAE) should be established and promoted.

Keywords Adult Literacy Programme (ALP), Developing Nations, Sustainable Development Goals (SDGs), Technology

\section{Introduction}

Literacy education is the bedrock of any society towards building the capacity of humans and brings about economic development Easton [1]. As the world moves from knowledge economy to digital economy, there is need for all sectors including education to embrace information and communication technology. In line with the demands of United Nations 2030 agenda, Sustainable Development Goals were adopted in September 2015 for every nation to achieve all the 17 Sustainable Development Goals (SDGs) because the international community recognizes that education is essential for the successful attainment of all the goals. On the other hand, following prediction and recent activities in the line of the Fourth Industrial Revolution (4IR), the role of technology in aiding the achievement of the identified Sustainable Development Goals (SDGs) is inevitable. A review of the work of 
Uleanya and $\mathrm{Yu}$ [2] shows that education is an enabling tool for the attainment of the disruptions that will be experienced following the Fourth Industrial Revolution (4IR). In this regard, technology and education are considered as tools working together in order to aid the attainment of both the identified Sustainable Development Goals (SDGs) and the disruptions to be experienced during the Fourth Industrial Revolution (4IR). Meanwhile, adult education is one aspect which seems to have been neglected in many African nations following the level of emphasis on the type of education and access given to young people or children of school age. However, the provided education that is envisaged to aid the attainment of the Sustainable Development Goals (SDGs) cuts across adult education / adult literacy programme. This study seeks to explore digital technology with regards to progress made towards achieving the fourth Sustainable Development Goal (SDG 4) among Adult literacy learners in developing nations. Meanwhile, the role of literacy education in using technology is critical to Technology initiative in adult literacy programmes in developing nations. The need for adult learners to embrace technology in literacy programmes considering the large usage of mobile technology among learners is numerated and further propagated. Ref. [3] opine that Information and Communication Technologies (ICT) in adult education has the potential to serve as a catalyst for national development in developing nations, especially as it concerns rural parts of African countries. They added that non-formal education is also inclusive of adult education in this regard. However, the focus of this study is on the Adult Literacy Programme (ALP) in rural parts of African nations which are majorly described as developing nations. Thus, this study argues that the inclusion of digital device into lifelong learning such that technology can be relevant to adults' continuing education in diverse areas, especially as it concerns rural parts of African nations is pivot. It concluded by highlighting the lessons learnt from all these initiatives with the intention to ensure and enhance development in rural parts of African nations, cum meet the Sustainable Development Goals.

\section{Conceptualization of Terms}

Adult and Continuing Education: Adult and continuing education is a kind of education that refers to any learning undertaken by or provided for mature women and men outside the formal school setting Kocanova, Bourgeois and Coutinho [4]. In this study, adult and continuing education will be used to mean any form of training or education given to individuals above 15 years of age who do not have the opportunity to be part of any formal schooling system.

Literacy Education: There are several definitions for literacy education from various authors. However, Ishaq and Ali [5] define literacy as a concept that includes traditional literacy, critical literacy, cultural literacy, functional civic literacy. A review of the work of Ishaq and Ali [5] further shows that Literacy Education (LE) can be viewed as any form of education which explores ways of inculcating into people the ability to read and write, while taking into cognizance their environments where necessary and possible. Suffice to say that according to Ishaq and Ali [5] Literacy Education (LE) is envisaged to help make people functional wherever they find themselves following the LE skills acquired. This implies that LE is to make people functional in various ways, hence, ensuring that certain functional skills are acquired. Additionally, in congruence with the work of Ishaq and Ali [5], Kocanova, Bourgeois and Coutinho [4] consider literacy as the ability to read, write and compute to interpret information, to solve personal problems, within organisations, and make decisions in the society. According to the work of Kocanova, Bourgeois and Coutinho [4], Literacy Education (LE) is any form of training or schooling which empowers people with the skills of reading, writing as well as computing in order to be able to interpret information. In this study, Literacy Education (LE) will be used to mean education targeted at helping students to acquire the skills and abilities to read, write and compute in order to interpret information. These are channeled towards solving a range of problems which may be personal, organizational, societal, amongst others. Literacy Education (LE) is also used targeted at helping people make informed and useful decisions in the society.

Technology / E-learning: This is a form of learning which promotes the use of gadgets, equipment as well as networking [6, 7]. In other words, technology / e-learning allows students to learn using online platforms. In this study, technology / e-learning will be used to mean any form of education which provides access to equipment, new resources and networking that bring about modern development and flexible learning opportunities through formal, non-formal and informal pathways.

Rural Africa: Rurality varies from place to place Flora and Flora [8] as well as Uleanya, Gamede and Kutame [9]. Rural areas of developed nations differ from those of developing or underdeveloped nations which are predominantly African. This is due to the features which characterize each of these areas. For instance, according to Flora and Flora [9], rural areas in developed or advanced nations are usually characterised by non-existence of airports or rail stations. However, rural areas of underdeveloped or developing nations are characterised by high rate of illiteracy, unemployment, dispersed settlement, amongst others (Uleanya, Uleanya and Gamede [10] as well as Uleanya, Gamede and Kutame [9]. In the case of this study, following the notion that Africa is a continent with predominantly developing nations, rural Africa will be used to mean areas of African nations that are majorly characterised with high rate of unemployment, dispersed settlement, high level of illiteracy, underdeveloped, areas, 
amongst others.

\section{Problem Statement}

Education is a tool for ensuring change as well as sustainable development $[11,12,13]$. This form of education includes adults. This accounts for one of the reasons for the quest for basic education which is expected to give every citizen the platform to be exposed to education Easton [1]. The fact sheet released by the United Nations Educational, Scientifc and Cultural Organization [17] (UNESCO) (2017a) from the Institute for Statistics shows that from the total number of adult illiterates in the world, 27 percent live in Sub-Sahara Africa, 10 percent are from Eastern and Southern Asia, 9 percent are from northern Africa, Western Asia, while about 4 percent are from the Caribbean and Latin America. It is observed that Sub Sahara Africa and Southern Asia have the lowest literacy rates with Adult literacy rate below 50 percent in most countries. According to the Minister of Education in one of the developing nations in Africa, precisely: Nigeria, 37 million Nigerian adults are illiterates Premium Times [18]. Also, review of the work of Uleanya and Gamede [19] indicates that the level of illiteracy in Africa is high. This aforementioned suggests the low rate of adult literacy and the need for adult education programme. Meanwhile, the inclusion and use of technology in education is a major tool which enhances and promotes teaching and learning Uleanya and Gamede [17]. Suffice to state that technology use in adult education has the potency to ensure and promote the desired Sustainable Development Goals (SDGs). However, while adult education programmes in developing nations, especially those in Africa, the inclusion and use of technology in enhancing such is questionable. Hence, the reason for this study which seeks to explore how Sustainable Development Goal in Africa, specifically developing nations such as Nigeria, South Africa, Ethiopia, Kenya, amongst others are being ensured through Adult Literacy Programme (ALP) using technology. In an attempt to achieve the aim of the study, attempts will be made to proffer answers to the following research questions: How can Sustainable Development Goal 4 be achieved through technology usage in adult literacy programmes? What are the challenges hindering adult literacy programmes from ensuring sustainable development in developing nations?

\section{Research Methodology}

The research approaches adopted in this study are review and case study. Meanwhile, case study in educational research could be a system, an institution, a programme, a classroom, a group, a person or an event which is available for study or investigation in order to bring up available solutions to the grey areas within the subject matter. According to Obadara [18], it is a research in which only a social unit which may be a state in the country, a community, a tribe, an institution, an individual or group of individuals is studied to find out what is amiss or wrongly placed in order to correct the wrongs and introduce ideas that would add values to such systems or situations. Ref. [19] further stressed that this type of research requires an in-depth and a systemic study of a particular illustration so as to generate knowledge. In this regard, the focus is a case of developing nations, especially as it concerns African countries. In undertaking this case study, review method is adopted. In this regard, relevant literatures on the use of technology in developing nations ensure Sustainable Development Goal through Adult Literacy Programme (ALP).

\section{Concept of Literacy and Sustainable Development Goals}

Literacy is a fundamental step in achieving a lifelong learning in order to improve the quality of life, livelihood and work. Literacy education gives new opportunities to individuals in various spheres of life, basically to improve in areas such as accessibility to information, knowledge management, interpersonal relationship, social services, work ethics and industrial production Hanemann [20]. However, these new opportunities are not accessible to those who lack the knowledge, skills, and the competencies to access the digital world hence, they end up being marginalized in the increasing digital driven world because literacy is a vital skill Brown and Czerniewicz [21].

The evolution of new knowledge, skills and competence in the digital world, aligns with the need to be literates. Hence to bridge the literacy skills gap and reduce inequalities, we need to identify the challenges and future thrust in promoting literacy in the present digital driven societies. As noted by [22], the world has at least 758 million adults and 263 out of school children still lacking basic literacy skills despite the progress being made.

The usage of information and communication technology (ICT) is directly changing the approach of people on how they live and work, learn and socialize. On the other hand, ICT encourages others who are into administrative services, health care and agriculture. It enables them to deliver in a more accessible and efficient manner.

Several initiatives have been launched in developing nations which are predominantly African countries. For instance, in South Africa, the "KhaRiGude Literacy Campaign; and in Nigeria, the National Commission for Mass Literacy was established with the aim of empowering non-literate adults and out-of-school youths with basic and functional literacy skills Mckay [23], amongst others. There have been other initiatives in Nigeria such as the effects of mobile technology on adult learners' 
achievement in literacy programme in Ibadan, the use of WhatsApp to promote literacy among adult learners and the use of Two ICT based technology to promote literacy $[6,7]$ and $[32]$.

Literacy activities are embraced to fully eradicate all the programmes that bring inequality into the fabric through mobilization, advocacy, engagement with policy makers and mass sensitization in developing nations. For instance, in the year 2000, 189 world's heads of states met at the United Nations and came up with a set of 8 goals known as the Millennium Development Goals (MDGs) which later was metamorphosed into the 17 Sustainable Development Goals (SDGs) in September 2015. One of the vocal goals of the SDGs is Goal number 4 which is aimed at "ensuring inclusive and equitable quality education and promote lifelong learning opportunities for all UNESCO [24]. According to the Agenda for Sustainable Development 2030, education is central to the realization of the 2030 Agenda for Sustainable Development Goals. Education being fundamental plays important roles in the Sustainable Development Goals because it directly contributes to all the SDGs and not restricted to only SDG 4.

The Sustainable Development Agenda 2030 is a universal plan to eliminate poverty through sustainable development agenda by 2030 . While adopting this agenda in the year 2015, the international communities and head of states acknowledged that education was indispensable for the success of all the 17 goals. Motivations for education are fundamentally captured in 2030 Sustainable Development Goal 4 which aims to "ensure inclusive and equitable quality education and promote lifelong learning opportunities for all": adults inclusive UNESCO [24].

Sustainable Development Goal 4 which comprises 10 targets addressing different areas of educational matters. Seven out of the ten targets are expected outcomes and the remaining three serve as the means of implementing these targets. Exploring digital technology to support the progress towards achieving Goal 4 of the SDGs agenda, particularly target 4.6 on youth and adult literacy. There are also education elements in the targets of several of the other 16 SDGs which are a way for adult learners, putting all current issues such as climate change, child protection, sanitation and hygiene education, safety and security amongst others into consideration to move us further into achieving Sustainable Development Goals UNESCO [22].

Despite the efforts of world leaders and international organisations in establishing different programmes such as SDGs, the rate of literacy is still low in most parts of the world, especially in Asia, Latin America and Africa. Ref. Pehrsson [25] submits that a large portion of the population in the developing economy still struggle with illiteracy and the ability to read, write or participate actively in the economy- a situation that continues to make Africa the continent with the lowest number of literates. In recent years, there has been an increasing interest in the use of mobile technology across the African continent. For instance, African Business Community [26] reported that smart phone users in Nigeria spend 193 minutes on the devices, 131 minutes on the television, 80 minutes on laptops and 39 minutes on tablets. According to the report, on a daily basis, 69 percent of Nigerians watch videos on their mobile phones; 19 percent do so weekly, 13 percent rarely and two percent do same monthly.

Additionally, the report of Broadcasting Board of Governor [27] and the work of Udensi [28] indicate that an average of nine to ten high school education certificate holders personally own mobile devices compared to $71.3 \%$ of those with less than a secondary school qualification. Ref. Broadcasting Board of Governor [27] as well as the work of Udensi [28] further show that the population of mobile device users are more concentrated among adults with those between the ages of 25-34 with (89.3\%), followed by ages 35 and older with (78.8\%) while those below the age of 24 years lack the purchasing power suppressing the rate among younger Nigerians [27] [28].

\section{Findings and Discussion}

The findings following review of relevant literatures are as explained below following the identified research questions guiding the study.

\section{How can Sustainable Development Goal 4 be achieved through technology usage in adult literacy programmes in developing nations?}

Following reviewed literatures, Sustainable Development Goal 4 (SDG4) are achievable through technology usage in adult literacy programmes in developing nations. However, certain things are to be taken into consideration. For instance, according to Ariya, Ogundele, Abiodun and Saleh [3], there is need for adult learners to know the reason of their learning. Meanwhile, the learning to be made available to them is to be characterised in the following ways amongst others: ensure relevance, be inclusive of their real-life every day needs and experiences both professional and personal. Also, learning in adult education programme is to be made to be self- directed. For these to be achieved, the need arises to incorporate the use of modern gadgets which are in alignment with Information Communication Technology (ICT). Ref. [3] further add that in the use of Information Communication Technology (ICT) in adult education in developing nations, the learning must be learner centred regardless of the barriers that may be associated with the use of ICT gadgets in teaching and learning to enhance Sustainable Development. Meanwhile, Oyedeji [29], considers on the job training important for adult learners. Thus, adult education programmes are to take into cognizance the jobs, working conditions and time of adult learners, so as to be able to make their learning experiences 
relevant. However, Onasanya [30] opines that the inclusion and use of ICT in adult education programmes will help to ease the burden and aid the training of adult learners. This finding of this study implies that technology is crucial in making adult literacy programmes successful in developing nations. The success of such programmes through the use of technology is contributory to the attainment of the desired sustainable goals.

\section{What are the challenges hindering adult literacy programmes in developing nations from ensuring sustainable development?}

Review of extant literature such as [3] [19] [31] amongst others highlight various challenges that are faced by learners in adult education programmes. The challenges amongst others include: access to various possibilities, application of the technologies, quality and cost Ariya, Ogundele, Abiodun and Saleh [3], distraction, adopted teaching strategies, assessment from instructors, feedbacks $[16,17]$. Additionally, low availability or lack of internet access, poor electricity supply, expensive cost of personal computer and internet-enabled phone as well as the required technical support Adelore and Itasanmi [31]. Meanwhile, Adelore [32] in congruence had earlier identified feedback as one of the challenges of adult education learning programmes. He however added that challenges such as spacing of content for learners, quizzes and learner support are also contributory to adult education programmes Adelore [32]. This implies that as important as adult education programmes are to the attainment of the desired Sustainable Development Goal 4 (SDG4), several challenges tend to work towards the achievement of such.

\section{Situations and Lessons learnt in the context of developing nation as Nigeria}

The under listed situations and lessons were generated from the studies carried out in Nigeria by [6,7]. The findings of the studies indicate that learners have the opportunities of going through their classes anywhere they so wish with or without much technological involvement. The usage of technology will enable learners to access their scores promptly, practice any module; receive feedback and corrections immediately they access the platform. The aforementioned studies established that most facilitators did not have technical know-how of the use of Information and Communication Technology. Also, the Nigerian environment lacks many of the required resources to support adult literacy programmes in order to achieve the sustainable development goals agenda. Thus, the need arises to explore how to overcome digital divide and lack of infrastructure. Digital divide in this regard is used to mean existing gap between regions with quality access to contemporary Information, Communications Technology (ICT), and those with less or restricted access.

\section{Overcoming the digital divide and lack of infrastructure}

Different scholars have highlighted various ways of overcoming digital divide and lack of infrastructure following the importance and usefulness of ICT in the societies. For instance, [33] opines that policy is a major tool that can be instrumental in overcoming the identified challenge. This implies that policies aiding the reduction or possible eradication of digital divide and lack of infrastructure are to be considered and explored. This can be in the area of inclusion of ICT content in the curriculum of students in various school levels, policies promoting the provision and availability of computers for students, availability of internet facilities in public domains, amongst others. On the contrary, [34] states that the availability of internet facilities to students can be a source of distraction, thereby hampering their academic success. However, Steele [35] emphasizes the need for digital literacy. According to Steele [35], digital literacy aids individuals' acquisition of knowledge on how to put to use pieces of information made available by ICTs as well as internet technologies. In other words, with digital literacy put in place, individuals in the nation will be able to acquire the right information, avoid distraction while surfing the internet, use the right acquired information for the desired good purposes. Other ways of overcoming digital divide according to Steele [35] include: making it affordable for the masses, ensuring that contents posted online are relevant to users, internet infrastructure development being largely encouraged and promoted by relevant stakeholders in the society, encouragement of the use of internet facilities, amongst others. Suffice to state that overcoming the challenge of digital divide and lack of infrastructure encompasses the efforts of different stakeholders in the society. These stakeholders may include the government, business owners, private individuals, amongst others.

\section{Conclusions and Recommendations}

In conclusion, this paper sought to establish how Sustainable Development Goal through Adult Literacy Programme can be ensured using technology in Nigeria. Review method was adopted while focusing on Nigeria as a case study. The findings of the study established that education is a tool for achieving Sustainable Development Goal (SDG). Meanwhile, technology can be used as a teaching and learning instrument and a model designed that can effectively help adult learners to respond to specific needs and ultimately increase the level of adult literacy rate. It is also the belief of the researchers that there is need to fully integrate technology into Adult Literacy Programmes, to help in achieving the Sustainable Development Goal 4 agenda by 2030 . Sequel to the findings of the study, the following recommendations are made: 
- All stakeholders should look beyond the traditional education lens and embrace the usage of digital inclusivity for improved literacy education and lifelong learning. Such technology can be relevant to adult learners in areas like e-Health, Agricultural extension services, e-security, e-Administration / e-government services, including green and environmental services, even in our daily routine domestically such as more sustainable consumption and production patterns.

- The main responsibility for continuous awareness and implementation of the policy lies with the national body, international organisations and partners providing assistance through coordinated policy advice, technical support, capacity development, supervision and monitoring of progress at regional, national and local levels.

- There is also the need to increase government support for adult literacy programmes by funding various initiatives that support same.

- It is very important to create a national programmes that would involve adult learners who would serve as the pilot groups to use technology to learn.

- Establishment of collaborative efforts across several governments such as the Department of Information Communication and Technology, and Department of Adult education.

- Other African countries can engage in such initiatives, as well as collaborative initiatives with Nigeria to achieve Sustainable Development Goals as a continent.

- Researchers need to extensively respond to the growing need for research in this area, especially by developing platforms that work for the use of technology in the improvement of knowledge delivery to adult learners.

\section{Limitation and Suggestion for Further Study}

This study was limited to review of relevant literature using Nigeria as case study. Hence, it is suggested that similar study should be replicated empirically using quantitative, qualitative or mixed methods approach. Also, the study can be conducted in two or more African nations or other nations outside the continents.

\section{REFERENCES}

[1] P. Easton, Sustaining Literacy in Africa Developing a Literate Environment. United Nations Educational, Scientifc and Cultural Organization (UNESCO), Paris, 2014

[2] C. Uleanya, K. Yu, Review of Preparedness of Rural African
Communities Nexus Formal Education in the Fourth Industrial Revolution. South African Review of Sociology. https://doi.org/10.1080/21528586.2019.1639074

[3] D. Ariya, M.O. Ogundele, D.Y. Abiodun, S. Saleh, The Role of Information and Communication Technologies in Adult Education and Non Formal Education for National Development in Nigeria. Asia Pacific Journal of Education, Arts and Sciences vol.2, No.1, 31 - 36

[4] D. Kocanova, A. Bourgeois, A.S. de Almeida Coutinho, Adult Education and Training in Europe: Widening Access to Learning Opportunities. Eurydice Report. Education, Audiovisual and Culture Executive Agency.

[5] A. Ishaq, M. Ali, Effective Planning as a Potent Tool for Implementing Adult Literacy Programmes : Implications for Achieving the Millennium Development Goals in Gombe State , Nigeria . Journal of Economics and Sustainable Development vol.3, No.6, 93 - 99 .

[6] O. Adelore, M Akintolu, Effects of Mobile Technology on Adult Learners' Achievement in Literacy Programmes in Ibadan. Nigeria Journal of Social Work Education vol.15, No.IX, $187-199$.

[7] M. Akintolu, O. Adelore, D.R. Nzima, Attitude of Learners toward the Use of Mobile Technology for Adult Literacy Programme. Journal Of Gender, Information and Development in Africa vol.8, No.1, 63 - 82. https://doi.org/10.31920/2050-4284/2019/8n1a3.

[8] C.B. Flora, J.L. Flora, Rural communities: Legacy and change (4th ed.). Boulder, CO: Westview Press, 2013.

[9] C. Uleanya, B.T. Gamede, A.P. Kutame, Rural and Irrelevant: exploration of learning challenges among undergraduates' rural Universities. African Identities Journal.

https://www.tandfonline.com/eprint/J2SVMCP5YDQZCK7 Z9KQR/full? target $=10.1080 / 14725843.2020 .1767037$.

[10] C. Uleanya, B.T. Gamede, M.O. Uleanya, Distance Nexus Learning Challenges among Rural Undergraduate University Students. Journal of Gender, Information \& Development in Africa, vol.8, No.1, 129 - 144 (DOI: https://doi.org/10.31920/2050-4284/2019/8n1a4).

[11] D. Mitra, The Social and Economic Benefits of Public Education. USA: Pennsylvania State University, 2011.

[12] C. Uleanya, Y. Rugbeer, M.A.N. Duma, Localizing Educational Curriculum of Tertiary Institutions: Approach to Sustainable Development. Journal of Entrepreneurship Education, vol.21, No.3, $89-100$.

[13] M. Elfert, Lifelong learning in Sustainable Development Goal 4: What does it mean for UNESCO's rights-based approach to adult learning and education? International Review of Education vol.65, 537 - 556. https://doi.org/10.1 007/s11159-019-09788-Z

[14] United Nations Educational, Scientifc and Cultural Organization (UNESCO) 2017a. "Literacy Rates Continue to Rise from One Generation to the Next." Unesco 2016 (45): $1-13$.

[15] Premium Times. 60 Million Nigerians Are Illiterates. Premium Times, Nigeria. 2017.

[16] C. Uleanya, B.T. Gamede, Comparative Learning 
Challenges among Undergraduate University Students in Nigeria and South Africa. International Journal of Comparative Education and Development, vol.20, No.2, 90 100 .

[17] C. Uleanya, B.T. Gamede, Technology: Solution to Quality Rural University Education. International Journal of Interdisciplinary Educational Studies, vol.13, No.2.

[18] B. Obadara, Essentials of Research Methodology. First Publ. Lagos: New Age Publisher Limited, 2007.

[19] P. Rule, V. John, Your Guide to Case Study Research. Pretoria: van Schaik, 2011.

[20] U. Hanemann, Lifelong Literacy: Some Trends and Issues in Conceptualising and Operationalising Literacy from a Lifelong Learning Perspective. International Review of Education, vol.61, No.3, 295 - 326. https://doi.org/10.1007/ s11159-015-9490-0.

[21] C. Brown, L. Czerniewicz, Debunking the 'Digital Native': Beyond Digital Apartheid, towards Digital Democracy. Journal of Computer Assisted Learning, vol.26, No.5, 357 69. https://doi.org/10.1111/j.1365-2729.2010.00369.x.

[22] United Nations Educational, Scientifc and Cultural Organization (UNESCO) 2017b. "Unpacking Sustainable Development Goal 4 Education 2030 Sustainable Development Goals United Nations Educational, Scientific and Cultural Organization GUIDE." UNESCO EDUCATION SECTOR.

[23] V.I. Mckay, Kha Ri Gude (Let Us Learn) Adult Literacy Programme (KGALP). UNESCO, 2012

[24] United Nations Educational, Scientifc and Cultural Organization (UNESCO). 2015. "UNESCO's Contribution to the 2030 Agenda for Sustainable Development."

[25] A. Pehrsson, International Strategies in Telecommunications. Models and Applications. Strategic Management in Tourism. https://doi.org/10.1079/9781845935887.0286.
[26] African Business Community. 2017. African Tech Startups Funding Rises $17 \%$ in 2016; South Africa, Nigeria, Kenya Most Popular Investment Destinations. Africa Tech. 2017.

[27] Broadcasting Board of Governor. 2014. Contemporary Media Use in Nigeria.

[28] E.U. Udensi, Social Media and Political Effects: A Case Study of the 2015 Nigeria's Presidential Election. International Journal of Social Science and Humanities Research, vol.3, No.2, $2348-3156$.

[29] N.B, Oyedeji, Management: principle and practices in education. Lagos: Aras Press, 2013

[30] S.A. Onasanya, Computer in education. In I. O. Abimbola (Ed). Fundamental principles and practice of Instruction. Ilorin: Department of CSET, University of Ilorin, 2001

[31] O. Adelore, A. Itasanmi, The Use of Two ICT Tools in Adult Literacy Programmes: Lessons Learned. Journal of Education and Practice, vol.7, No.20, 138 - 44.

[32] O. Adelore, Using Whatsapp Mobile Application as Tutorial Delivery Tool for Advanced Level Learners in Adult Literacy Programmes: Lessons Learned. African Journal for The Psychological Study of Social Issues (AJPSSI), vol.20, No.1, $131-139$

[33] B Shenglin. F. Simonelli. R. Zhang. W. Li. Digital infrastructure: Overcoming Digital Divide in Emerging Economies. Online available from https://economic-policy-forum.org/wp-content/uploads/20 17/03/Policy-Brief_ZJUCEPS_Digital-infrastructure Over coming-Digital-Divide-in-Emerging-Economies_2017022 8.pdf.

[34] C. Uleanya. B.T. Gamede. Technology: Solution to Quality Rural University Education. International Journal of Interdisciplinary Educational Studies, Vol.13, No.2, 59-74. https://doi.org/10.18848/2327-011X/CGP/v14i02/59-74.

[35] C. Steele. Top Five Digital Divide Solutions. Online available from http://www.digitaldividecouncil.com/top-fiv e-digital-divide-solutions/. 